\title{
A GARANTIA DOS DIREITOS FUNDAMENTAIS SOCIAIS FRENTE À SUPREMACIA DO INTERESSE PÚBLICO DECORRENTE DA RESERVA DO POSSÍVEL
}

Manoel Ilson Cordeiro Rocha

\section{RESUMO}

A crise do Estado Social reforça o conflito entre a garantia dos direitos fundamentais sociais no Estado Social e a prerrogativa estatal de definir as políticas públicas sociais, respaldado na supremacia do interesse público e no limite da reserva do possível. Esse artigo desenvolve o caminho para a ponderação necessária nesse conflito de princípios.

Palavras-chave: Direitos fundamentais sociais. Supremacia do interesse público. Reserva do possível.

\section{INTRODUÇÃO}

A crise do Estado Social afetou principalmente a efetivação dos direitos sociais constitucionalizados no século XX sob o discurso da restrição de recursos e da má gestão pública. $\mathrm{O}$ discurso neoliberal hegemô- 
nico das últimas três décadas produziu reformas restritivas de direitos em conflito com os interesses protegidos nas Constituições.

Mas até que ponto a renúncia aos direitos sociais não significa uma renúncia à democracia e ao Estado de Direito? E até que ponto é possível retroceder diante da legitimidade de tais direitos perante o imaginário popular e perante a solidez das instituições que reconhecem esta legitimidade? A antinomia entre os pilares da revolução liberal de liberdade e igualdade renova-se com o déficit produzido pelo Estado neoliberal e a promessa da revolução - de emancipação do indivíduo - é novamente adiada.

Condicionada e consequente desse debate, encontra-se a questão dos limites aos direitos fundamentais, em especial os sociais, enquanto prerrogativa do Estado para definir quais são os direitos realmente devidos e como efetivá-los ou enquanto conjunto de direitos constitucionalmente garantidos e inerentes ao pacto social vigente. A natureza dos limites aos direitos fundamentais, em especial os sociais, mais do que uma questão de teoria do direito e modo de interpretação de um direito fundamental, é uma questão fundamento ideológico do Estado.

A doutrina da "reserva do possível", fundada na ideia de que ad impossibilita nemo tenetur (ninguém é obrigado a coisas impossíveis), apresenta-se como axioma, mas esconde esse debate ideológico. Por outro lado, a definição do que é e do que não é possível nas sociedades complexas contemporâneas é, muitas vezes, definir o que é e o que não é prioritário, conforme o status quo. Há uma diferença entre o que é absolutamente impossível, em condições racionais, razoáveis e consensuais, e o que é impossível conforme as opções das forças sociais hegemônicas. Essa distinção interfere na linha de legitimidade do instituto e na força de seu argumento.

Diante da disputa sobre os direitos fundamentais sociais, a reserva do possível, fundada na supremacia do interesse público, contrapõese, muitas vezes, à proteção da dignidade da pessoa humana e à garantia de um mínimo essencial de proteção desses direitos. É preciso, portanto, definir o que é interesse público e se esse está voltado ao bem comum, só assim se solucionará esse conflito a contento.

Aqui se pretende identificar em que medida a reserva do possível é uma limitação legítima aos direitos fundamentais sociais e como se insere na problemática da interpretação e efetivação de tais direitos. 


\section{CRISE DO ESTADO SOCIAL E PRECARIZAÇÃO DOS DIREITOS FUNDAMENTAIS SOCIAIS}

\subsection{O contexto de crise do Estado Social}

Delineamos este capítulo, a partir da concepção de Estado Social como ordem político-jurídica moderna, fundada na proteção social e na segurança econômica, garantida pela intervenção do Estado nos limites da democracia e do Estado de Direito. Juridicamente se manifesta pela constitucionalização de direitos de natureza social ${ }^{1}$, de responsabilidade do Estado, garantidos efetivamente pela forte intervenção estatal na economia. A presença do Estado na economia, que foi o grande debate do século XX e sobre o qual aqui não é preciso delongar, evoluiu para um capitalismo de Estado forte, fundado no keynesianismo.

O modelo de Estado Social foi também uma resposta à polarização entre liberalismo e socialismo, por isso mesmo não significou apenas um modelo de gestão pública, mas de uma verdadeira configuração ideológica. Esta caracterização é, naturalmente, expressa no domínio constitucional, onde os princípios formaram-se num conjunto coerente e coeso com o modelo. Sua expansão ocorreu principalmente após a segunda guerra mundial nos países europeus continentais, mas contemplou um universo maior, que é relativamente representado ainda hoje pela OCDE (Organização de Cooperação e Desenvolvimento Econômico).

Teve vigorosos êxitos no pós-guerra e por três décadas parecia a melhor opção de regulação social. Mas, em meados dos anos setenta, as sociais-democracias entraram num ciclo de inflação, desemprego crescente e déficit de produtividade, com a consequente elevação dos custos da proteção do desemprego, com a erosão do poder aquisitivo pela inflação e a elevação constante dos custos dos demais serviços sociais e de burocracia pública. O que foi prontamente associado à incapacidade do Estado de financiar a proteção social e de participar da gestão da economia. As políticas públicas, para garantir o pleno emprego por via de investimentos na economia e refinanciamento do ciclo produtivo, mostraram um Estado mau gestor, principalmente porque não atuava sobre a lógica da competitividade. Por outro lado, o ciclo crescente de benefícios públicos, fundado

\footnotetext{
${ }^{1}$ Calcado no discurso humanista do século XX, expresso nas Constituições garantistas de direitos fundamentais de segunda geração.
} 
em valores éticos emancipadores do indivíduo em sociedade, com mais serviços e garantias, não foi acompanhado pelo respectivo crescimento de receita ${ }^{2}$. O Estado social deparou-se com a crítica neoliberal de que ele é conceitualmente inviável.

De fato, o Estado Social acreditou demasiadamente na fórmula keynesiana de que a resposta do investimento público na economia seria suficiente para suportar o crescimento das demandas sociais. Não considerou, devidamente, o crescimento da burocracia, as vicissitudes da riqueza privada e a demasia das demandas sociais com o crescimento e envelhecimento da população. Por fim, o sistema político funcionou sob a lógica eleitoral e momentânea, sem um planejamento estável e de longo prazo.

As crises do petróleo da década de 70 impulsionaram a derrocada do Estado Social. Primeiro, porque comprometeram os orçamentos públicos com a elevação dos custos da principal fonte energética, acelerando o endividamento dos Estados e os subjugando às avaliações de decisões do sistema financeiro internacional. Segundo, porque forçaram uma corrida por tecnologias alternativas e por sistemas operacionais de produção pós-fordistas que reduzissem custos e garantissem competitividade. Esses novos modelos, entre eles as flexibilizações legais das relações de trabalho, a abertura dos mercados e o toyotismo, vieram acompanhados de exigências de gestões públicas também mais dinâmicas, flexíveis e, principalmente, eficientes e de baixo custo.

Sob a perspectiva da globalização dos mercados, uma nova ordem social moldou-se gradativamente, com reflexos contundentes nos sistemas políticos e jurídicos. O modelo anterior, de maior consistência da soberania, de legitimidade fundada em políticas públicas garantidas e de crescimento econômico estatista, foi substituído pela abertura de mercados, crise do Estado Social e investidor e emergência de novos atores nas relações de poder, oriundos da sociedade globalizada.

\footnotetext{
2 Para Jorge Miranda, a crise do Estado social é "derivada não tanto de causas ideológicas (o refluxo das ideias socialistas ou socializantes perante ideias neoliberais) quanto de causas financeiras (os insuportáveis custos de serviços cada vez mais extensos para populações activas cada vez menos vastas), de causas administrativas (o peso da burocracia, não raro acompanhada de corrupção) e de causas comerciais (a quebra da competitividade, numa economia globalizante, com países sem o mesmo grau de protecção social" (MIRANDA, Jorge. Manual de Direito Constitucional, Tomo I. Coimbra: Coimbra; 1996, p. 98).
} 
Mas apesar das reformas neoliberais, o cenário atual ainda é de uma máquina pública agigantada e de custo elevado. Isso porque os governos neoliberais e também a chamada terceira via depararam-se com uma máquina burocrática irrefreável, assim como constataram que as reformas esbarram num limite perigoso: se atingirem um patamar muito maior de cortes de serviços públicos podem desencadear um ambiente de convulsão social. Por outro lado, se há um consenso de que as medidas tomadas até então foram necessárias, o que se discute é o modo de como reformar o Estado.

Esse problema é ainda emergente, porque os Estados estão, de regra, no limite suportável de suas cargas tributárias e já cortaram o que aparentemente seria possível cortar. Entretanto, a adoção pública de técnicas privadas de gestão passa a ser uma importante alternativa à solvência do Estado, e isto já se verifica com a defesa e emprego de princípios que lhes são típicos, como o princípio da eficiência.

\subsection{A desregulação e a precarização dos direitos sociais}

Esse ambiente de crise produz a desregulação e a precarização dos direitos sociais, sob o eco do discurso de reforma do Estado. Aos poucos, são introduzidas reformas constitucionais que afetam a proteção dos direitos sociais. A revisão constitucional portuguesa de 89, ao mudar o caráter interventivo do Estado, no fundo fragilizou a proteção aos direitos fundamentais sociais. No Brasil, sucessivas emendas constitucionais promoveram reformas no sistema previdenciário, na presença do Estado na economia, no controle do orçamento público, sempre no sentido de reduzir o Estado e a sua capacidade de intervenção. Não necessariamente todas as medidas denominadas neoliberais significaram uma afetação à proteção dos direitos fundamentais sociais, mas é possível fazer uma generalização do fenômeno sob o argumento de que, em conjunto, as reformas pertencem a uma orientação ideológica restritiva de tais direitos.

Sob a ótica dos efeitos do Estado neoliberal no debate jurídico, há duas perspectivas: a defesa dos direitos sociais, com fundamento na orientação constitucional, ou a adesão ao discurso reformista com uma gradual precarização da prestação dos serviços. O problema agrava-se porque, se de um lado as conquistas do Estado Social são por si só legítimas, não se pode ignorar os fundamentos da crise do Estado, com o seguinte questionamento: a insistência em preservar um Estado juridica- 
mente social sob a égide de um Estado politicamente neoliberal é uma inconsequência ou uma resistência? Porque de duas uma: ou alimentará um desequilíbrio entre os que estão protegidos por força da lei e os que não estão, ou se instaurará uma farsa de um sistema jurídico alienado da realidade e sustentado puramente na sua retórica. Assim como não podemos negar o papel e o direito da sociedade civil de resistir às opções do Estado.

É preciso que a resposta jurídica à crise do Estado Social considere a importância do seu legado, assim como também os fundamentos que levaram à crise são intimamente ligados à efetivação dos direitos sociais. Trata-se de uma promessa política e juridicamente irrealizável, resumida num brocardo jurídico: ad impossibilita nemo tenetur (ninguém é obrigado a coisas impossíveis). Como, juridicamente, equalizar a reserva do possível com a garantia dos direitos fundamentais?

\section{A PRERROGATIV A DOS DIREITOS FUNDAMENTAIS SOCIAIS NO ESTADO DEMOCRÁTICO E DE DIREITO}

Os direitos fundamentais foram identificados e garantidos em gerações que, em essência, se contrapõem3. O conjunto das liberdades individuais de primeira geração impõe ao Estado obrigações negativas, no sentido de se abster de seu caráter interventivo em prol da efetivação desses direitos. Politicamente, significou uma conquista do pensamento e da ideologia liberal clássica, de motivação econômica burguesa. De outro modo, o conjunto de direitos sociais de segunda geração impõe ao Estado obrigações positivas, que dependem do seu caráter interventivo em prol da efetivação destes direitos. Politicamente, seja atendendo à agenda ideológica socialista ou à agenda socialdemocrata, essa segunda geração implicou em conquistas sociais contrárias ao ideal liberal de Estado ${ }^{4}$.

\footnotetext{
3 Apenas para posicionar devidamente a oposição entre os direitos fundamentais e os limites do Estado a estes direitos é que se faz necessário discorrer brevemente sobre o seu status. Não é nenhuma proposição de debater os fundamentos do Estado de direito, mas há algumas premissas a pontuar, necessárias para o que vem a seguir.

${ }^{4}$ Esta distinção não pode ser ignorada - ainda que a dicotomia entre capitalismo e socialismo tenha se esvaziado ou mesmo ainda que a social democracia esteja em crise -, porque este rol de direitos permanece e são legitimamente reivindicados em sociedade.
} 
O artigo 18, número 1 da Constituição da República de Portugal vincula expressamente todos os poderes do Estado aos direitos fundamentais. Também a Constituição Federal do Brasil reconhece a prerrogativa dos direitos fundamentais. A ideia de Constituição democrática é indissociável do projeto moderno de emancipação do indivíduo, entendido como a antítese à medievalidade, ao propor a ruptura com a sociedade estamental pela promoção de liberdades fundamentais e da igualdade.

Incapaz de resolver plenamente a contradição entre liberdade e igualdade, o Estado liberal conferiu um sentido esvaziado de igualdade, caracterizado pelo formalismo e pela estrita configuração de igualdade perante a lei. Mas como promessa da modernidade de emancipação do indivíduo, a igualdade ganhou evidência no século XX e renovou a antinomia com as liberdades fundamentais. O problema dos Estados liberais e dos socialistas sempre foi a necessidade de resolver essa antinomia, seja para um lado ou para o outro, a socialdemocracia procurou a compatibilização e mesmo após a sua crise, no Estado neoliberal, essa perspectiva não foi superada.

O problema da reserva do possível tem esse debate de fundo. "As exigências de igualdade material só podem ser assumidas enquanto exigências constitucionais porque do princípio constitucional da socialidade decorre uma necessária superação da compreensão da igualdade como mera igualdade formal perante a lei geral e abstrata" ${ }^{\text {. A }}$ igualdade material produzida pela intervenção do Estado em sociedades democráticas sob concepção social democrata tem gradativamente perdido espaço em reformas restritivas denominadas neoliberais. Por outro lado, a história nos ensinou que o livre mercado é incapaz de promover justiça social.

\section{A DOUTRINA DA RESERVA DO POSSÍVEL}

\subsection{O conceito de reserva do possível}

\footnotetext{
${ }^{5}$ NOVAIS, Jorge Reis. Os princípios constitucionais estruturantes da república portuguesa. Coimbra: Coimbra Editora, 2004, p. 298.
} 
O argumento de apoio da doutrina da "reserva do possível" é, a princípio, muito forte: a efetivação dos direitos fundamentais depende da ação do Estado pela promoção de serviços públicos que, em certa medida, estão condicionados à existência de recursos e aos demais limites de execução encontrados na estrutura pública. Porém, estes recursos não são suficientes para todas as expectativas criadas no Estado Social ${ }^{6}$. Há um brocardo jurídico que a doutrina aplica ao problema: ad impossibilita nemo tenetur (ninguém é obrigado a coisas impossíveis). Como afirma Vieira Andrade, "para que o Estado possa satisfazer as prestações a que os cidadãos têm direito, é preciso que existam recursos materiais suficientes e é preciso ainda que o Estado possa dispor desses recursos". E continua o autor: "os direitos a prestações materiais do Estado correspondem a fins políticos de realização gradual ou que são direitos 'sob reserva do possível"" 7 .

A natureza jurídica da reserva do possível é de um verdadeiro limite aos direitos fundamentais, mas de conotação distinta dos clássicos limites, ou seja, é uma restrição às obrigações positivas do Estado, deixando de fazer o que, a priori, deveria fazer. Gomes Canotilho identifica quatro possíveis acepções do instituto:

1. 'Reserva do possível' significa total desvinculação jurídica do legislador quanto à dinamização dos direitos sociais constitucionais consagrados; 2 . Reserva do possível significa a 'tendência para o zero' da eficácia jurídica das normas constitucionais consagradoras de direitos sociais; 3. Reserva do possível significa gradualidade com dimensão lógica e necessária da concretização dos direitos sociais, tendo, sobretudo, em conta os limites financeiros; 4. Reserva do possível significa insindicabilidade jurisdicional das opções legislativas quanto à densificação legislativa das normas constitucionais reconhecedoras de direitos sociais" $"$. Em todas

\footnotetext{
${ }^{6}$ Entretanto, há que se distinguir, como apontamos a princípio, entre o que é absolutamente impossível, em condições racionais, razoáveis e consensuais, e o que é impossível conforme as opções das forças sociais hegemônicas.

${ }^{7}$ ANDRADE, José Carlos Vieira de. Os direitos fundamentais na Constituição portuguesa de 1976. Coimbra: Livraria Almedina, 1983, p.201.

${ }^{8}$ CANOTILHO, J. J. Gomes. Metodologia ‘fuzzy' e 'camaleões normativos' na problemática atual dos direitos econômicos, sociais e culturais. In: Canotilho, J.J. Gomes (co-
} 
elas, verifica-se a liberdade do legislador em definir o momento de prestação do serviço de promoção dos direitos sociais.

Quanto à sua abrangência, a reserva do possível pode ser tanto uma barreira relativa, diante de uma limitação jurídica pela inexistência de previsão orçamentária, como pode ser uma barreira absoluta, pela limitação fática da inexistência dos recursos. E quanto à sua extensão, pode ocorrer tanto na efetivação dos direitos sociais - pela sua estrita vinculação à prestação de serviços públicos - quanto também pode ocorrer na efetivação das liberdades fundamentais - em menor medida, mas reflexamente no conjunto de ações públicas que garantem o Estado de Direito e a democracia, pois as obrigações negativas também implicam em ônus público, quando a abstenção do Estado se insere no conjunto das políticas públicas e como custos gerais não individualizados. Entretanto, a doutrina tende no sentido de identificar a reserva do possível apenas na promoção dos direitos sociais, pois são esses que dependem de maior condicionamento material.

Por outro lado, o condicionamento dos referidos direitos a uma definição orçamentária não pode ser interpretado como uma resposta definitiva para o problema, porque, se de um lado o orçamento é um complexo de natureza política maleável e sujeito a uma margem de variação interpretativa, muitas vezes apenas jurídica, de outro lado, os direitos sociais como princípios constitucionais possuem um caráter de normatividade que se impõe à legislação orçamentária e, portanto, depende de uma solução de conflito.

$\mathrm{O}$ recorte jurídico-estrutural de um direito não pode nem deve confundir-se com a questão do seu financiamento. Se essas duas dimensões fossem indissociáveis, então não se compreenderia que certos direitos - como o direito de acesso aos tribunais - pudessem tranquilamente ser considerados como direitos diretamente aplicáveis e, não obstante isso, estejam dependentes de prestações

ord.). Estudos sobre direitos fundamentais. Coimbra: Editora Coimbra, 2004, p. 107/108. 
estatais (tribunais, processos, patrocínio judiciário, etc. $)^{9}$.

Por fim, outra questão atinente à definição da reserva do possível é a sua vinculação às funções do Estado. É necessário saber se é uma competência executiva, se é legislativa, ou se é apenas de uma interpretação do texto constitucional. Há de contemplar a legitimidade condizente com a separação de poderes e até que ponto esse limite não é um empecilho à efetivação dos direitos. De um lado, as Constituições consagram e normatizam um conjunto de direitos, em especial direitos sociais que demandam as respectivas obrigações positivas, e de outro, é uma competência para definir o orçamento e a parcela que caberão a essas obrigações, assim como a disponibilidade executiva para os serviços nos limites dos recursos em recorrentes situações de descompasso entre a oferta e a demanda. Enfim, há um desequilíbrio entre a promessa constitucional e a realidade, e resta ao Direito responder, pela jurisprudência e pela doutrina, como isso se legitima ou que direção deve tomar com fins a obter a resposta legítima.

O problema é particularmente diferenciado em países como Portugal e o Brasil, onde a consolidação da democracia e a opção por um Estado Social não foi acompanhada por um nível de crescimento econômico e distribuição de riqueza equivalentes aos países mais centrais.

\subsection{A reserva do possível e os direitos de liberdade}

Considerando que não é necessário aqui distinguir os direitos fundamentais entre suas gerações ${ }^{10}$, comporta então definir que, se há uma estrita relação entre a reserva do possível e os direitos sociais, o

${ }^{9}$ CANOTILHO, J. J. Gomes. Metodologia 'fuzzy' e 'camaleões normativos' na problemática atual dos direitos econômicos, sociais e culturais. In: Canotilho, J.J. Gomes (coord.). Estudos sobre direitos fundamentais. Coimbra: Editora Coimbra, 2004, p. 108/109.

${ }^{10}$ Favorável a uma distinção entre os direitos fundamentais, Vieira Andrade afirma o seguinte: "embora tenhamos adoptado o conceito de direito subjetivo em sentido amplo para designar o lado subjetivo dos direitos fundamentais, temos agora de distinguir entre os direitos, liberdades e garantias, enquanto direitos 'determinados' e os direitos sociais, enquanto direitos a "prestações não vinculadas" (ANDRADE, José Carlos Vieira de. Os direitos fundamentais na Constituição portuguesa de 1976. Coimbra: Livraria Almedina, 1983, p. 205). 
mesmo não se pode dizer quanto aos direitos de liberdade, ou direitos de primeira geração, que dependem mais da omissão do que da ação do Estado. Ainda que aparentemente, sejam direitos que não implicam em custos elevados ao Estado, eles indiretamente os possuem. Por exemplo, o direito à vida está indiretamente ligado à promoção da segurança pública e os direitos políticos dependem de estrutura eleitoral.

A questão é que tanto os direitos sociais quanto as liberdades têm facetas positivas e negativas. Não cabe distinguir as liberdades individuais dos direitos sociais, mas sim os limites que são decorrentes das obrigações positivas do Estado, mas que acabam por coincidir com os direitos sociais. Há equivalência entre as liberdades individuais e os direitos sociais enquanto direitos plenamente reivindicáveis, e está superada a idéia de que os direitos sociais são meramente normas programáticas. Para Novais, é exatamente a reserva do possível que distingue as duas categorias de direitos fundamentais. Quando uma liberdade depende de uma ação positiva, como o direito a um mínimo para existência como decorrência do direito à vida, trata-se aí de um direito social.

\subsection{A reserva do possível e o mínimo para a existência}

No direito português a Constituição da República (artigo 18, número 3 , fine) impõe a proteção ao "conteúdo essencial dos preceitos constitucionais" contra as leis restritivas. Pressupõe, portanto, a existência de um núcleo essencial dos direitos inatacáveis tanto pelo legislador quanto pelo administrador. Também as jurisprudências alemã, portuguesa e brasileira ${ }^{11}$ afirmam a existência desse núcleo essencial.

Na doutrina, há importantes contribuições a respeito: "o conteúdo essencial de todos os direitos deverá sempre ser assegurado, e só o que estiver para além dele poderá deixar ou não de o ser em função do juízo que o legislador vier a emitir sobre a sua maior ou menor relevância"12. Ou por Vieira Andrade, "não poderá designadamente admitir-se que o conteúdo essencial (enquanto núcleo fundamental) possa ser afectado,

\footnotetext{
${ }^{11}$ Cito estes países apenas porque os dois últimos nos interessam especialmente, e o primeiro influiu nos demais neste tema.

12 MIRANDA, Jorge. Manual de Direito Constitucional. Tomo IV: Coimbra: Coimbra Editora, 2008, p. 434.
} 
mesmo que um bem considerado superior o exigisse ou parecesse exigir"13, e no mesmo sentido se posiciona Paulo Bonavides ${ }^{14}$.

O mínimo para a existência se fundamenta na perspectiva de efetividade dos direitos fundamentais. Não é um direito com um fim em si, mas um meio e uma garantia. Se os direitos fundamentais não se encontrarem amparados pela perspectiva de mínima realização resultarão numa dispersão própria de normas programáticas, de mero vislumbre e idealização. O problema é como averiguar esse mínimo, pois admiti-lo é também atribuir a uma máxima ou média realização dos direitos como perspectivas ideais, sem a certeza do direito. Noutras palavras, no extremo, pode-se concluir que "o mínimo" é a plena realização dos direitos, senão não teria razão de existir.

Outro problema é auferir este mínimo, pois qual seria a referência para a sua satisfação: o padrão de riqueza da sociedade, a tradição e a cultura, uma valoração ética subjetiva etc.? Por exemplo, qual é o mínimo de recursos para a prestação de serviços de saúde pública? A oferta de tratamentos eficazes ou a oferta de tratamentos atuais, que sob a perspectiva da saúde são mais eficazes à medida que produzem menos efeitos colaterais ou menos riscos de insucesso no tratamento?

O que ocorre é que há uma contradição entre a sistemática de direitos fundamentais, que são equilibrados entre si de acordo com as circunstâncias de cada caso, e a oposição de um núcleo absoluto inderrogável. Essa contradição é mais clara se observarmos a natureza desse núcleo: ou o que se visa é proteger o núcleo essencial de um direito, juspositivamente configurado, e aí é possível o intérprete identificar por critérios valorativos os contornos desse núcleo, de natureza geral e abstrata, mas se nega a condição subjetiva que cada direito tem para cada titular, segundo as particularidades de sua vida, ou tal dispositivo visa proteger um direito subjetivo individual, mas que ignora a conformação do direito às exigências da vida em comunidade, que sempre impõe restrições necessárias aos direitos. Também a relativização de um juízo de ponderação e proporcionalidade esvazia a concepção de essencialidade do direito.

\footnotetext{
${ }^{13}$ ANDRADE, José Carlos Vieira de. Os direitos fundamentais na Constituição portuguesa de 1976. Coimbra: Livraria Almedina, 1983, 191.

${ }^{14}$ BONAVIDES, Paulo. Curso de Direito Constitucional. São Paulo: Malheiros, 2007, p. 645 .
} 
Por outro lado, se o mínimo essencial é conceitualmente imensurável, significa que os direitos sociais estão sujeitos à condenação e extinção diante da ditadura dos cofres vazios? Não, porque a reserva do possível não está no mesmo plano dos direitos fundamentais. Esses existem, em especial os direitos sociais, independentemente de sua efetividade e sujeitos às condições de proporcionalidade e reserva do possível, como veremos adiante.

Também o fundamento de um núcleo essencial dos direitos não se confunde com a preservação da dignidade da pessoa humana. A promoção dos direitos fundamentais, em especial os direitos sociais, não visa outra coisa senão uma existência digna ao homem, mas o princípio da dignidade da pessoa humana é um conceito jurídico indeterminado e depende de conformação. Na verdade, trata-se de um princípio de natureza genérica, ou seja, está relacionado a um conjunto de outros princípios e direitos que, em conjunto produzirão a dignidade ${ }^{15}$.

O princípio da dignidade da pessoa humana é reconhecido formalmente em muitos sistemas jurídicos, como em Portugal e no Brasil, mas a sua conformação a partir de um mínimo para a existência não é absolutamente seguro.

\subsection{A reserva do possível e a supremacia do interesse público}

O interesse público é aquele expresso na realização do bem comum, é o instrumento para a sua realização. Ainda que haja dificuldade para definir o que é o bem comum, podemos entender que esse significa, num Estado democrático e de direito, a conjugação dos seus vários princípios, realizados otimamente. A realização otimizada dos fundamentos eleitos por uma sociedade só é possível, diante do provável conflito de

\footnotetext{
${ }^{15}$ A dignidade é o traço distintivo do ser humano, que o reconhece como único e titular de uma individualidade, caracterizado por sua racionalidade e autonomia da vontade. A capacidade humana de arbítrio o dota da peculiar condição de resposta exclusiva e autônoma, fruto da reflexão e distintiva das demais respostas de seus pares. Esta condição é motora da própria existência humana e até do hipotético pacto social. Portanto, a sua preservação está acima de qualquer outra regulação social. Mas a proteção da individualidade humana, que o confere como único e digno, depende de uma existência livre e socialmente realizada, ou seja, só é efetiva na medida em que é reconhecido como titular do conjunto dos direitos fundamentais. Não se pretende aqui esgotar a problemática da dignidade da pessoa humana, apenas distingui-la da ideia de um "mínimo para a existência".
} 
interesses, pela atenção proporcional e ponderada aos interesses em conflito ao máximo possível. O bem comum é a razão de ser da própria organização social, do Estado e do direito.

Para se afirmar que o interesse público é a realização do bem comum, é preciso compreender que ele não pode ser visto como uma prerrogativa arbitrária do Estado. Se assim o for não promoverá o bem comum, ainda que seja o interesse do Estado. Cada sociedade nomeia o interesse público que lhe convém e não pode ser diferente disso para não se cair num postulado vago e sem sustentação. O que confere legitimidade ao interesse público e à sua supremacia num Estado democrático e de direito é exatamente a realização da democracia e do Estado de direito, enquanto síntese do interesse público desse Estado. Ainda que esta condição confira uma demasiada abstração, ele não perde a relevância enquanto motor e síntese de todas as ações de Estado úteis a cada um dos seus princípios.

Não se trata de um princípio geral que legitima toda e qualquer ação do Estado, o que seria um postulado de autoritarismo e de prerrogativa absoluta sobre direitos fundamentais. O interesse público, legítimo por promover o bem comum, deve conjugar os demais princípios do Estado democrático e de direito e em especial promover os direitos fundamentais. É mais do que um princípio, é uma ideia de síntese dos princípios. Para que não assuma a conotação autoritária, primeiro, tem que demonstrar efetivamente que é voltado para o bem estar da coletividade. Segundo, ele deve resultar do exercício de ponderação, principalmente no sentido de se preservar os interesses privados configurados pelos demais princípios e direitos fundamentais.

Só assim podemos dizer que o interesse público coincide com interesses privados, pois o que é bom para a coletividade é bom para cada particular. Mas é possível que um interesse particular específico, de satisfação pessoal, coincida com o interesse público, quando esse está livre de outros interesses concorrentes. Portanto, o interesse público não é a somatória dos interesses privados, mas é essencialmente a somatória dos fins de determinada sociedade. Em cada caso, o juízo de ponderação e proporcionalidade avaliará o que deve prevalecer e essa opção é a opção do interesse público. É de interesse público que os interesses privados legítimos sejam satisfeitos. Quando, porém, há conflito de interesses e um deles atende à coletividade, aí há um indício de interesse público, plenamente confirmado quando o juízo de proporcionalidade indicar que dar 
prioridade àquela pretensão coletiva será mais socialmente útil e mais efetivo na promoção de direitos em conflito.

Por outro lado, esta orientação do que é o interesse público esvazia o seu conteúdo de critério definidor de opção pelo intérprete, já que assim qualquer opção pode ser de interesse público. Porém, não perde o caráter de legitimação da decisão, como uma síntese superior dos vários princípios na decisão ponderada do intérprete. Bandeira de Mello conceitua interesse público também no sentido de conjunto de interesses da coletividade que são também privados, quando não ferem os interesses maiores da coletividade: "o interesse público deve ser conceituado como o interesse resultante do conjunto de interesses que os indivíduos pessoalmente têm quando considerados em sua qualidade de membros da Sociedade e pelo simples fato de o serem" ${ }^{16}$. Por consequência, e é isto muito importante, também os interesses do Estado não são todos interesses públicos, há os interesses individuais do Estado que, ainda que legítimos, conflituam com o conjunto dos interesses da coletividade.

É nesse sentido que a atenção à reserva do possível não se trata apenas de uma constatação de incapacidade do Estado e da sociedade de satisfazer as promessas da democracia social, mas também de um pressuposto legítimo na busca do bem comum, garantido pela instrumentalidade da supremacia do interesse público. O conjunto de promessas do Estado Social nunca foi devidamente mensurado diante da capacidade e recursos do Estado, tanto que suas normas sempre foram postas apenas como programáticas. $\mathrm{O}$ reconhecimento dos direitos sociais subjetivos, porém, não pode perder a sua perspectiva de distribuição equânime e racionalizada.

No sentido também de apontar a supremacia do interesse público, destacam-se doutrinas que apontam limites aos direitos fundamentais fundadas na diferenciação entre o público e o privado, com reconhecimento de alguma prevalência do primeiro. Nesse sentido, é a doutrina da "cláusula de comunidade", desenvolvida pelo Tribunal Administrativo Federal alemão, e significa que existem exigências mínimas da vida em sociedade, ou valores elementares sem os quais a sociedade não poderia subsistir e que qualquer direito fundamental, para a sua efetivação, depende de se verificar se não põe em perigo os bens jurídicos necessários à existência da comunidade. Trata-se de um limite imanente do próprio direito fundamental, verificado no caso concreto quando se terá em vista

${ }^{16}$ MELLO, Celso Antônio Bandeira de. Curso de direito administrativo. São Paulo: Malheiros, 2003, p. 58. 
o conflito com os interesses da comunidade. Reis Novais ${ }^{17}$ aponta a crítica a tal doutrina, por se fundar numa garantia da ordem pública, que pode se generalizar a que qualquer bem jurídico seja essencial à existência da comunidade, sem limitação em detrimento de direitos fundamentais. Além do mais, o legislador já indicou as reservas aos direitos fundamentais, e os limites da ordem pública já foram definidos, como no artigo 18 da Constituição Portuguesa. Significa, portanto, também uma usurpação da competência do legislador de definir os limites. Também Vieira Andrade critica a doutrina da "cláusula de comunidade", considerada vaga e por "não dar apoio seguro a uma aplicação racional e fundada dos preceitos fundamentais" $"$.

Entretanto, o problema continua, e se essa doutrina é perigosa e contraditória, é inegável que há um interesse público a ser tutelado e muitas vezes em oposição a direitos fundamentais. Se o reconhecimento de uma prevalência de interesses públicos entra em conflito com a garantia de direitos fundamentais, o problema que temos é identificar a fronteira entre esses interesses e os direitos. Se esta fronteira não é clarificada pela cláusula de comunidade, ela estará na opção do legislador ao definir concretamente as obrigações positivas do poder público e nos casos difíceis, na ponderação entre interesse público e direito fundamental. Portanto, a supremacia do interesse público é relativa, na medida em que no caso concreto se justifique.

\section{OS DIREITOS FUNDAMENTAIS DIANTE DA RESERVA DO POSSÍVEL}

\subsection{Os limites aos direitos fundamentais e a separação de poderes}

A Constituição é a última salvaguarda dos direitos fundamentais, e qualquer dos poderes do Estado está sujeito a ela. Porém, mais do

\footnotetext{
${ }^{17}$ NOVAIS, Jorge Reis. As restrições aos direitos fundamentais não expressamente autorizadas pela Constituição (tese de doutoramento). Lisboa: Faculdade de Direito de Lisboa, 2002, p. 410/411.

${ }^{18}$ ANDRADE, José Carlos Vieira de. Os direitos fundamentais na Constituição portuguesa de 1976. Coimbra: Livraria Almedina, 1983, p. 218.
} 
que direitos sob a guarda da Constituição, os direitos fundamentais, como um todo, confundem-se com a própria Constituição democrática e não cabe discutir a validade desses direitos, apenas os seus limites imanentes. Os direitos fundamentais como essência da Constituição é a outra face de uma sociedade que reconhece a titularidade do poder ao povo e por isso precisa garantir aos cidadãos o resguardo contra o Estado.

Mas além dos limites negativos, a Constituição democrática do Estado Social também garante, aos cidadãos, condições sociais que ampliam a sua emancipação e o exercício pleno da democracia. A efetividade dos direitos sociais, porém, não pode comprometer os demais fundamentos da democracia, já que o fim desses direitos não é outra coisa senão ela própria. Neste contexto é que se assenta a separação de poderes, como mecanismo de autocontrole do Estado, em proteção dos cidadãos contra o seu abuso e dominação, e também contra qualquer ação que vise comprometer a realização da democracia, inclusive em restrições ilegítimas na promoção dos direitos sociais.

Diante da imanência de limites aos direitos fundamentais, em especial aos direitos sociais, o princípio da separação de poderes é relevante tanto para distribuição de atribuições referentes à efetividade dos direitos, quanto também como instrumento de limite aos limites em prol da democracia, quando um poder fiscaliza o outro no exercício de limitação dos direitos. Além de fundamentar os limites aos limites, a separação de poderes, seguindo a construção de Montesquieu, atribui ao legislativo a competência para definir os limites imanentes dos direitos, em especial os direitos sociais que dependem de previsão orçamentária. "O conteúdo dos direitos de prestação é, portanto, em última análise, determinado pelas disposições do legislador ordinário, atuando por delegação constitucional" 19 . A responsabilidade para densificação dos direitos é do legislador, mas ao executivo também cabe a regulamentação das leis e estruturação dos serviços e ao judiciário cabe o crivo de constitucionalidade e de ponderação nos conflitos entre direitos fundamentais e outros interesses.

O problema que afeta a separação de poderes na configuração dos limites aos direitos, em especial os direitos com obrigações positivas como os direitos sociais, é a fronteira entre a competência do legislador e a apreciação de constitucionalidade do juiz. Assim como também a fronteira entre a competência do administrador de prestação destas obrigações

${ }^{19}$ ANDRADE, José Carlos Vieira de. Os direitos fundamentais na Constituição portuguesa de 1976. Coimbra: Livraria Almedina, 1983, p. 202. 
nos limites da legalidade e da discricionariedade e novamente a competência do juiz em decidir sobre as opções do administrador em oposição aos direitos fundamentais, num juízo de ponderação que não pode contrariar a decisão discricionária. Porém, a opção discricionária, fundada na legalidade, confronta-se com a prevalência dos princípios constitucionais. O problema amplia-se quando o administrador, ao restringir a prestação de um serviço público, o faz sob a alegação da reserva do possível. Porque ainda que ele esteja condicionado pela vinculação da dotação orçamentária, há sempre aí alguma margem de discricionariedade, decorrente, por exemplo, da escolha da qualidade, da extensão, da prioridade, etc. A Administração não está sujeita a um controle jurisdicional apenas de legalidade, mas também de juridicidade, onde até o seu âmbito de discricionariedade pode ser revisto ante os princípios constitucionais.

Se o ponto de partida é a competência do legislador para definir o conteúdo concreto dos direitos sociais, e aí não há que se falar em interferência do judiciário, exceto quando se discute exorbitância de competência, o ponto de chegada é a efetividade desses direitos, pois cabe ao administrador determinadas competências de regulamentação e cabe ao legislador conformar o direito constitucionalmente reconhecido. Até que ponto o legislador tem o dever de conformar um respectivo direito social constitucional? Forma-se aí um poder-dever? E quando conformar, que limites aos limites ele se sujeita, numa possível apreciação judicial de constitucionalidade? É claro que todas essas questões são demasiadamente amplas para o que se pretende aqui, mas delas se extrai a consequência da fundamentação legítima da reserva do possível por parte do legislador. Como afirma Vieira Andrade:

Para que se determinem como direitos, é necessária uma actuação legislativa que defina o seu conteúdo concreto, fazendo opção num quadro de prioridades a que obrigam a escassez dos recursos, o caráter limitado da intervenção do Estado na vida social e, em geral, o próprio princípio democrático"20. No mesmo sentido Afirma Jorge Miranda: “A apreciação dos factores económicos para uma tomada de decisão quanto às possibilidades e aos meios de efectivação dos direitos cabe aos órgãos

${ }^{20}$ ANDRADE, José Carlos Vieira de. Os direitos fundamentais na Constituição portuguesa de 1976. Coimbra: Livraria Almedina, 1983, p. 207. 
políticos e legislativos - não aos da administração. Não corresponde a uma simples operação hermenêutica, mas a um confronto complexo das normas com a realidade circundante ${ }^{21}$.

É necessário responder a cada uma das questões sob a perspectiva da separação de poderes, tendo por referência os consensos que já existem nesse tema. A começar pela obrigação do legislador de conformar os direitos sociais na medida em que esses dependam de legislação de limitação, regulação e clareamento. Trata-se de um dever do legislador, porque os direitos sociais não são uma liberalidade sua, a ponto da decisão sobre legislar ou não se configurar como uma decisão política, entretanto, as opções que naturalmente surgirão sobre o modo de efetivação é de solução de natureza política e discricionária. Também é onde a reserva do possível aparece como um dos componentes mais influentes, já que a demanda de serviços sempre foi, é e sempre será demasiadamente superior à disponibilidade de recursos.

Por outro lado, ainda que se configure a falta do legislador e justifique a consequente intervenção do judiciário, essa ocorrerá basicamente em duas hipóteses: primeiro, pela legislação exorbitante, que fere e contraria a concepção hermenêutica do direito constitucional, onde então será declarada inconstitucional e, segundo, pela lacuna da omissão legislativa, que também dispõe de um instrumento de declaração de inconstitucionalidade, mas conceitual e efetivamente frágil, exatamente por conta do princípio da separação de poderes. Pode o judiciário declarar a inconstitucionalidade por omissão, mas não pode efetivamente fazer o legislador legislar ou sequer pretender legislar no lugar dele. Como afirma Vieira Andrade: "o legislador não pode decidir se actua ou não. É lhe proibido o 'non facere'. Se ele não emitir as medidas necessárias para tornar exequíveis as normas relativas aos direitos sociais, poderá incorrer em inconstitucionalidade por omissão"22 . Comentando a declaração de inconstitucio-

\footnotetext{
${ }^{21}$ MIRANDA, Jorge. Manual de Direito Constitucional. Tomo IV: Coimbra: Coimbra Editora, 2008, p. 434.

${ }^{22}$ ANDRADE, José Carlos Vieira de. Os direitos fundamentais na Constituição portuguesa de 1976. Coimbra: Livraria Almedina, 1983, p. 206.
} 
nalidade por omissão, Reis Novais também é pessimista quanto à sua efetividade ${ }^{23}$.

A segunda questão, relativa ao recurso da reserva do possível pelo administrador, o problema maior é quando não há omissão do legislador, mas sim uma reserva de discricionariedade necessária deferida à administração. A norma que confere a discricionariedade, pela impossibilidade de previsão exaustiva do legislador, poderá ser a abertura para que o juiz decida entre um direito fundamental e outro interesse, possivelmente outro direito fundamental. Mas a solução adotada pelo juiz não tem, obrigatoriamente, a mesma direção da opção administrativa, porque ao juiz cabe decidir ponderada e proporcionalmente conforme os interesses em conflito, enquanto que o administrador decide politicamente. Porém, se a discricionariedade é exatamente uma certa liberdade de escolha que não cabe a ingerência do juiz, pela ausência de objetividade que o legislador identificou para aquela situação, não haverá discricionariedade onde a escolha implicar numa contrariedade aos princípios constitucionais. Depois de filtradas as inconstitucionalidades, nas hipóteses onde há um direito de prima facie e há outros interesses em jogo, a serem equalizados pelo administrador e controlados (o que é uma decisão vinculada, pois o correto é que não se confunda com a discricionariedade) pelo juiz.

Ao comentar a jurisprudência brasileira em capítulo anterior, foi demonstrado exatamente aí a escolha pragmática do STF. No afã de respeitar a separação de poderes e conferir um mínimo de efetividade aos direitos sociais, o que são duas premissas legítimas, decide-se contra a reserva do possível no controle concreto e a favor no controle abstrato, e talvez seja essa a melhor solução.

Por outro lado, ainda que a separação de poderes garanta a conveniência e a oportunidade legislativa e administrativa, essas não se confundem com a arbitrariedade. É a situação a princípio apontada do controle jurisdicional sobre a exorbitância da discricionariedade, cujos limites encontram-se na Constituição. A garantia de um direito na Constituição significa que não pode haver um grau zero de vinculação, mas mais do que nenhuma prestação de serviço, a prestação também não pode ser ridícula, numa medida que ilude e se faz absolutamente ineficaz, por princípio de boa razão e coerência. Mas o minimamente eficaz não é o mesmo que o mínimo para a existência e dignidade da pessoa humana, pois esse

23 NOVAIS, Jorge Reis. Os princípios constitucionais estruturantes da república portuguesa. Coimbra: Coimbra Editora, 2004, p. 300. 
último é um juízo de valor, sujeito a uma apreciação íntima do que cada um acha que lhe cabe diante de sua história, seus valores, seu ambiente, etc. Enquanto que o mínimo razoavelmente eficaz é um juízo técnico e de acordo com os padrões de ciência, urbanismo e coletivismo de cada época.

Entretanto, o juízo do mínimo razoavelmente eficaz não resolve o problema do limite da reserva do possível, apenas impõe a melhor ponderação e proporcionalidade à prestação do serviço e à garantia do direito fundamental, quando o juiz decidir entre a precarização do serviço em níveis ineficazes, decorrente da distribuição equânime dos recursos, e a garantia de direitos discriminadamente conforme esse juízo de ponderação. Se a precarização ineficaz significa a não prestação e garantia, a outra opção significa a garantia, discriminada, de algum direito. Nesse sentido o judiciário promove uma correção na efetividade dos direitos sociais, mas, no fundo, o problema continua sem uma solução adequada.

\subsection{Doutrinas de solução de conflitos que envolvem normas constitucionais}

Tais conflitos resultam da imposição de limites aos direitos fundamentais e da necessidade de controle constitucional a esses limites ${ }^{24}$. Tais direitos são naturalmente propensos a conflitos entre si, fruto da composição de interesses socialmente opostos e da indeterminação dos conceitos, uma vez que são direitos normalmente garantidos por princípios. "A solução dos conflitos e colisões não pode ser resolvida com o recurso à idéia de uma ordem hierárquica entre os bens para sacrificar os menos importantes" "25. Para harmonizá-los as Constituições estabelecem limites expressos ou permitem ao legislador estabelecer regras de regulação, clareamento e restrição, promovendo a conformação do direito.

\footnotetext{
24 Toda a discussão anterior sobre limites e limites aos limites é o pressuposto para o que vem a seguir. Na verdade, o que se está em análise é uma das mais densas e relevantes questões da teoria do direito e do Direito Constitucional. O conflito entre normas constitucionais implica na própria fundamentação e legitimação do Estado de Direito atual bem como do constitucionalismo atual.

${ }^{25}$ ANDRADE, José Carlos Vieira de. Os direitos fundamentais na Constituição portuguesa de 1976. Coimbra: Livraria Almedina, 1983, p. 221.
} 
Reis Novais ${ }^{26}$ resume a evolução deste debate a três doutrinas principais, todas de inspiração alemã: a teoria externa, a teoria interna e a teoria dos direitos fundamentais enquanto princípios. A teoria clássica é a teoria liberal externa, segundo a qual os direitos fundamentais limitam-se pela intervenção externa do Estado, pois são fundados na pré e supraestatalidade da liberdade. A liberdade é em princípio ilimitada, e excepcionalmente admite limites pelo Estado. Essa excepcionalidade é definida pela lei no interesse público, e, de regra, prevalece a liberdade. A reserva de lei compatibiliza interesse público e liberdade individual ${ }^{27}$. Porém, essa concepção não conseguiu abarcar a evolução dos direitos fundamentais no sentido de garantir socialmente as condições de exercício da liberdade, porque pressupõe a intervenção do Estado uma ação negativa minimalista, e não uma cooperação positiva realizadora dos direitos. A liberdade é aí uma reserva individual contra o Estado e o direito, o que se contradiz porque, antes de tudo, a liberdade é juridicamente garantida pelo próprio Estado e pelo direito. Ainda que os direitos fundamentais condicionem o legislador, eles são, por princípio, direitos.

Para esse modelo, o âmbito de proteção de um direito fundamental não coincide com o âmbito de garantia constitucional. Naquele há a possibilidade de intervenção restritiva desde que observados os limites aos limites. Esse último é um núcleo mais restrito onde não cabem restrições. Porque quando o legislador impõe uma restrição a um direito ele está objetivamente restringindo esse direito, mas o direito em si não é afetado, enquanto direito subjetivo. Afetar o direito em si significa uma inconstitucionalidade. Traduzindo a doutrina, Novais resume que,

do âmbito de protecção, deduzida a ocorrência, efectiva ou potencial, de restrições legítimas, chegase, finalmente, ao âmbito definitivo de protecção ou âmbito de garantia efectivo relativamente ao qual toda intervenção estatal desvantajosa será

\footnotetext{
${ }^{26}$ NOVAIS, Jorge Reis. As restrições aos direitos fundamentais não expressamente autorizadas pela Constituição (tese de doutoramento). Lisboa: Faculdade de Direito de Lisboa, 2002.

${ }^{27}$ Idem., p. 269/270.
} 
configurada como restrição ilegítima, como violação de direito fundamental ${ }^{28}$.

Mas uma restrição não é legítima ou ilegítima em função de estar ou não no âmbito de proteção efetiva, mas sim, estar ou não justificada materialmente dentro dos limites aos limites, porque são eles que ditarão a fronteira entre estes âmbitos.

"Neste sentido, a este modelo credita-se a vantagem de reconhecer devidamente a força normativa da Constituição e das distinções nela expressas, o que, aliado a uma metódica de controlo das intervenções compatível com a subsunção e o método jurídico tradicional, proporcionaria uma objetividade de resultados e uma segurança jurídica que não estariam ao alcance de qualquer dos outros métodos" ${ }^{\prime 29}$.

Mas, segundo Novais, é precisamente aí que se encontra sua desvantagem, pois se funda exclusivamente nas diferenciações abstratas do legislador constituinte, não contempla a imprevisibilidade que possui um sistema de princípios, conferindo, caso a caso, uma situação diferente, mesmo que sob os mesmos direitos. A CRP, com o artigo 18, número 2, primeira parte, precisa então resolver esta contradição. $\mathrm{O}$ faz exatamente no mesmo artigo 18 , número 2 , segunda parte, com o princípio da proporcionalidade, como veremos adiante.

Já a teoria interna, ou teoria institucional dos direitos fundamentais, pressupõe que a liberdade é um produto da sociedade e juridicamente constituída. "Os direitos fundamentais são a concretização jurídica da liberdade que, do ponto de vista dos fins do Estado, deve ser uma igual liberdade para todos, bem como uma liberdade integrada, limitada e vinculada aos interesses da comunidade" ${ }^{30}$. Inverte o sentido da liberdade se

\footnotetext{
${ }^{28}$ NOVAIS, Jorge Reis. As restrições aos direitos fundamentais não expressamente autorizadas pela Constituição (tese de doutoramento). Lisboa: Faculdade de Direito de Lisboa, 2002, p. 280.

${ }^{29}$ NOVAIS, Jorge Reis. As restrições aos direitos fundamentais não expressamente autorizadas pela Constituição (tese de doutoramento). Lisboa: Faculdade de Direito de Lisboa, 2002. p. 282.

${ }^{30}$ Ibidem.
} 
comparado com a teoria externa. O Estado e o direito não são mais uma ameaça, mas a própria realização da liberdade, e a atuação legislativa não é uma restrição, mas uma reserva de dois tipos: de conformação, segundo a necessidade de densificar o direito, e de delimitação ou ponderação, conforme conflitue com outros interesses jurídicos.

As reservas, conformando ou limitando o direito, são inerentes ao próprio conteúdo do direito e dele emanam para definir as suas fronteiras. Não se opõem ao direito, são uma necessidade para a sua concretização. A sua positivação tem caráter meramente declarativo ${ }^{31}$. A colisão com outros direitos ou valores é resolvida, pois onde não cabe um direito em detrimento de outro é porque aquele direito, de fato, não existe, não há colisão. Também a distinção da teoria externa entre âmbito de proteção e âmbito efetivamente reconhecido não faz mais sentido, pois o direito e os seus limites são uma única coisa, não há que se distinguir âmbitos. Há que apenas distinguir as hipóteses de violação, não há a distinção entre restrições legítimas e ilegítimas, pois não há restrições. Pela teoria externa, como a imposição aos direitos vem de fora, é possível distinguir entre restrições legítimas e ilegítimas, pois estão condicionadas aos limites a limites. Pela teoria interna, a imposição aos direitos vem de dentro e revela a sua própria identidade.

O problema dessa teoria está exatamente aí, ela não resolve a necessidade de controle da atividade do Estado, para proteção à violação dos direitos, e ainda retira a barreira que existia na teoria externa, de distinção entre direitos e restrições, já que formalmente pressupõe que os limites confundem-se com o direito. A imanência dos limites no próprio direito dispensa "as exigências de fundamentação dos resultados apurados, favorecendo, consequentemente, a legitimação de qualquer actuação dos poderes constituídos"32. Facilita o abuso de fundamentações manipuladas, em especial em Estados autoritários.

O terceiro modelo é o dos direitos fundamentais enquanto princípios. Nesse modelo a perspectiva não é de identificar a natureza dos limites e restrições, como nos modelos anteriores, mas de identificar a natureza dos próprios direitos e assim, compreender os limites. Para

${ }^{31}$ Idem, p. 288.

32 NOVAIS, Jorge Reis. As restrições aos direitos fundamentais não expressamente autorizadas pela Constituição (tese de doutoramento). Lisboa: Faculdade de Direito de Lisboa, 2002. p. 294. 
Dworkin $^{33}$, as normas distinguem-se em regras e princípios, nessa distinção se encontra os direitos de prima facie - dos princípios - e os direitos definitivos - das regras. Os princípios são direitos de prima facie, porque dependem de um juízo de ponderação entre os demais interesses jurídicos para se efetivarem. Dworkin demonstra que os princípios possuem uma normatividade diferenciada já que são autoaplicáveis, mas, nos casos difíceis apenas apontam um caminho, sem fixarem um resultado necessário. As regras funcionam na base do tudo ou nada.

Se propõe fundamentar a possibilidade de uma separação estrita e forte entre os dois tipos de normas - manifesta-se na diferente forma de aplicação e de colisão que, por sua vez, se funda na seguinte diferença essencial: enquanto que a dimensão fundamental das regras é a validade, a dos princípios é o peso ${ }^{34}$.

Os princípios permanecem válidos na ordem jurídica mesmo que preteridos numa determinada situação. É possível até que os mesmos princípios numa outra situação tenham prevalência invertida, em decorrência da diferença própria de cada caso. Na ocorrência de conflitos entre interesses, o que se verifica não é a natureza legítima ou ilegítima de restrições, como na teoria externa, e também não é o caso desses limites serem ou não imanentes dos direitos, como na teoria interna, mas sim se o direito é devido ou não em decorrência da ponderação entre regras e princípios.

Para Alexy ${ }^{35}$, a separação forte entre regra e princípio não impede uma interação entre eles, pois os princípios podem constituir uma exceção à regra, como quando as regras possuem conceitos indeterminados ou dependem de valorações que não permitem a mera subsunção. Ou, de outro lado, ao se introduzir cláusulas de reserva na solução de conflitos entre princípios, reduz-se a margem de ponderação. Assim, as regras passam a depender de uma não-aplicabilidade de princípios para a sua vali-

\footnotetext{
${ }^{33}$ DWORKIN, Ronald. Levando os direitos a sério. São Paulo: Martins Fontes, 2002.

${ }^{34}$ NOVAIS, Jorge Reis. As restrições aos direitos fundamentais não expressamente autorizadas pela Constituição (tese de doutoramento). Lisboa: Faculdade de Direito de Lisboa, 2002, p. 300.

${ }^{35}$ Idem, p. 302/305.
} 
dade, ou seja, perdem o caráter do tudo ou nada, e o princípio, condicionado a um pressuposto de cláusulas de reserva para a sua validade ou não, passam a uma aplicação de subsunção, sempre que não haja outro que se oponha a ele, o que é próprio das regras. Portanto, está comprometida a distinção forte entre regra e princípio. Mas Alexy afirma que a distinção persiste pelo caráter de prima facie dos princípios. Sendo os princípios realizáveis em maior ou em menor medida e as regras realizáveis porque são prescritas "dentro das margens do jurídica e facticamente possível"36, possuem um grau menor de indeterminação, sem uma preferência absoluta e definitiva, mas uma precedência, pela sua força vinculativa, em relação aos princípios, desde que, no caso concreto, não sobrevenha um princípio em sentido contrário. No conflito entre princípio e regra, não há apenas uma ponderação de peso, mas também o princípio terá que possuir razões que sobreponham as razões da regra. Com essa aproximação entre a regra e o princípio, Alexy conclui que os direitos fundamentais tanto podem surgir como princípios quanto como regras.

Mas a teoria dos princípios também sofreu críticas contundentes. Em especial, porque o seu fundamento de separação entre regras e princípios não se sustenta em casos difíceis, onde há grande complexidade e variabilidade de situações, principalmente diante da perspectiva de que muitas normas têm o duplo caráter de regra e de princípio, como o princípio da legalidade ou da igualdade que são também regras.

Em termos práticos, significa saber se estamos perante norma, constitucional ou infraconstitucional, susceptível de aplicação subjuntiva ou que careça ainda de ponderações, se o direito fundamental nela consagrado está ou não sujeito a restrições posteriores ou se a posição individual dele resultante é definitiva ou de prima facie $^{37}$.

Assim como também um determinado direito pode ser protegido numa norma-princípio e simultaneamente numa norma-regra.

\footnotetext{
${ }^{36}$ Idem, p. 304.

${ }^{37}$ NOVAIS, Jorge Reis. As restrições aos direitos fundamentais não expressamente autorizadas pela Constituição (tese de doutoramento). Lisboa: Faculdade de Direito de Lisboa, 2002, p. 317.
} 
Para resolver essa questão, Alexy distingue regras de princípios a partir da natureza de comandos de otimização dos princípios. No sentido de que esses devem ser realizados em maior medida possível, sendo a realização ótima somente uma, a que obtém a melhor realização. Porém, Novais ${ }^{38}$ afirma que a caracterização gradual de um direito em conflito não é a sua realização ótima - única e máxima -, mas a realização ponderada, porque o que se realiza gradualmente e em equilíbrio com outras pretensões jurídicas é o bem jurídico protegido e não o direito em si, esse sim é que pode ser otimizado, enquanto verificação de um grau máximo de efetivação. Entretanto nesse aspecto entendo que a distinção entre o bem jurídico e o direito em si não justifica a exclusão do juízo de otimização, como afirma Alexy. Porque o bem jurídico que se efetiva a partir de uma ponderação obtém também um resultado otimizado, de resposta última e máxima, que eventualmente pode ser a mesma aplicação otimizada do direito em si. A questão aqui é o que é o juízo de otimização. Segundo o próprio Novais ${ }^{39}$, "aquela que consegue a maior realização possível relativamente às possibilidades jurídicas e fáticas”. Ora, o que é "possível" não é estanque e definitivo, como pretende Novais. Novais quer conferir uma idéia de otimização distinta do processo de ponderação, o que não é necessário, a realização do ótimo não é inflexível e pode ocorrer tanto na proteção do direito em si quanto do bem jurídico decorrente desse princípio de direito.

A teoria dos princípios resolve uma questão crucial na interpretação na direito, de que na solução dos casos concretos não é possível se limitar à subsunção. Isto pelos seguintes motivos,

a vagueza da linguagem jurídica; a possibilidade de antinomias normativas; o fato de que pode não haver nenhuma norma disponível para a decisão de um caso; a possibilidade de aplicação do direito

\footnotetext{
${ }^{38}$ Idem, p. 319.

${ }^{39}$ NOVAIS, Jorge Reis. As restrições aos direitos fundamentais não expressamente autorizadas pela Constituição (tese de doutoramento). Lisboa: Faculdade de Direito de Lisboa, 2002, p. 319.
} 
contrária ao teor literal de uma norma em casos especiais ${ }^{40}$.

Esta evolução doutrinária nos revela a circunstância da efetivação legítima dos direitos fundamentais e como estes direitos subsistem em conformidade com os seus limites. A prevalecer a argumentação da teoria dos direitos fundamentais enquanto princípios, a reserva do possível se insere como um limite legítimo fundado no interesse público que deve ser ponderado na efetivação dos direitos sociais. A reserva do possível é um limite aos direitos fundamentais fundado na conjugação do princípio da proporcionalidade com o princípio da supremacia do interesse público, seja porque o poder público não pode oferecer o que não possui, seja porque ele deve oferecer proporcionalmente entre os cidadãos de acordo com o que ele dispõe. Por outro lado, a reserva do possível não pode significar a arbitrariedade do Estado, a contrariedade ao Estado de Direito e o comprometimento absoluto dos direitos fundamentais. Deve haver um equilíbrio e uma proporcionalidade entre esses interesses.

\subsection{Consideração da reserva do possível no juízo de ponderação}

Se a consideração da reserva do possível não pode ser ignorada na efetivação dos direitos sociais, a mesma segurança não há, na doutrina e na jurisprudência, quanto à sua validade e extensão no controle dos atos públicos de prestação material dos direitos.

A questão é que o juiz não dispõe da mesma liberalidade política do legislador e do administrador. Seu ato é vinculado, e a ponderação não é um juízo livre e opcional. O juiz não dispõe apenas do argumento irrefutável da limitação de recursos, vincula-se também à prevalência e normatividade dos direitos.

A ponderação entre os princípios, de forma a garantir os direitos fundamentais proporcionalmente à sua relevância em cada caso e a simultânea garantia dos interesses opostos é a orientação predominante hoje na solução dos conflitos de direitos e princípios fundamentais. A denomina-

\footnotetext{
${ }^{40}$ SOARES, Guilherme. Restrições aos direitos fundamentais: a ponderação é indispensável? In: MIRANDA, Jorge (coord.). Estudos em homenagem ao Professor Doutor Joaquim Moreira da Silva Cunha. Lisboa: FDUL, 2005, p. 336.
} 
da teoria dos princípios distingue as normas em regras e princípios, não nega a normatividade dos princípios, mas lhe atribui um caráter de generalidade e determinabilidade distinta da regra. Os princípios, em decorrência do seu grau de abstração, dependem de densificação e conformação, enquanto que as regras possuem aplicação direta. Assim, a regra proporciona uma aplicabilidade imediata, mas condicionada à certeza de sua correspondência ao fato, funcionando sob a lógica do tudo ou nada; já o princípio poderá ser aplicado à situação em medidas diferentes, conforme o juízo de proporcionalidade, ou mesmo não ser aplicado, sem que isso retire a sua validade, não sendo válido apenas naquelas condições fáticas.

Quando estão em causa direitos sociais, a ponderação aplica-se à proporcionalidade entre os recursos disponíveis pelo poder público, as regras de orçamento e o respeito à distribuição proporcional a garantir também os interesses e direitos sociais dos demais e a proteção em si dos direitos devidos reclamados.

O questionamento que se faz a essa solução é a possibilidade de se diluir demasiadamente a proteção sob o argumento da distribuição proporcional a um sem número de direitos prometidos pela Constituição, que comprometa a efetividade dos direitos. A ponderação enfraquece a condição de barreira dos direitos fundamentais. Mas se a ponderação significar um juízo criterioso, sem discricionariedade e arbitrariedade, em maior ou menor medida e de resposta mais realista às condições sociais, os direitos fundamentais serão garantidos.

A ponderação, segundo Alexy ${ }^{41}$, deve ocorrer em três fases: a verificação do grau de detrimento do direito fundamental; a determinação da importância da satisfação do bem jurídico oposto; e a determinação da justificativa de preponderância de um ou outro interesse. Nesse exercício, o interesse preponderante será proporcionalmente garantido se verificado que é adequado, ou seja, se a medida adotada irá produzir os objetivos a que se propõe. Simultaneamente se verifica se não há outra medida para satisfazer o mesmo fim e com menores prejuízos, bem como se a medida não ultrapassa o limite mínimo necessário para atingir o fim, e, por fim, deve se verificar se o ônus imposto justifica-se diante do bônus. Busca-se proibir os excessos.

${ }^{41}$ ALEXY, Robert. Teoria dos direitos fundamentais. São Paulo: Malheiros, 2008. 
A ponderação se faz sempre necessária, por que sempre haverá uma margem de indeterminação seja diante da natureza genérica dos princípios, seja diante da insuficiência das regras.

Quando o juiz decide por uma proteção a direito fundamental ignorando a alegação de incapacidade do Estado e a distribuição proporcional de acordo com esta capacidade, ele pode ferir a separação de poderes que atribuiu ao legislador desenvolver o planejamento orçamentário e pode ferir os direitos fundamentais de um número maior de pessoas que serão prejudicadas na prestação de serviços públicos por conta do privilégio conferido desproporcionalmente a um. Por outro lado, o legislador não faz e não possui competência para fazer uma discriminação individualizada dos direitos sociais de cada cidadão, o que compete ao administrador na sua competência discricionária ou vinculada. Pois está exatamente aí a dificuldade do juiz de discernir quando pode ou não interferir na competência executiva, confundindo por vezes o discricionário e o vinculado. O correto e o exato é que, tendo o legislador definido no orçamento e na legislação correspondente aos serviços públicos o rol e a extensão destes, haverá limites vinculados que o administrador deve obedecer e o juiz conferir, se provocado. Assim como haverá uma margem de discricionariedade ao administrador que o juiz não pode interferir.

Outra questão na ponderação diante da reserva do possível é a preservação de um mínimo indispensável à dignidade da pessoa humana. Questão que já foi abordada anteriormente e que terá algum desfecho aqui. Como apontado, principalmente inspirado nos argumentos de Reis Novais, o juízo deste mínimo é em si, contraditório. Mas abandonar a perspectiva de uma barreira de proteção dos direitos é incorrer no risco de autoritarismo e prevalência dos interesses de Estado típica da teoria interna e que, no fundo, fere o próprio Estado de Direito enquanto salvaguarda do indivíduo perante o Estado. A teoria dos direitos fundamentais como princípios é também uma resposta a esse problema, mas aqui, na mesma orientação dessa doutrina, temos algumas proposições a acrescentar.

A reserva do possível não pode significar uma burla às obrigações constitucionalmente garantidas. $\mathrm{O}$ nivelamento por baixo com base num mínimo essencial, além ser imensurável, impõe a um máximo de efetivação de direitos uma condição utópica indesejável. Porém, se a pretensão de promoção dos direitos fundamentais esbarra naturalmente na promessa demasiada e crescente de direitos como reflexo da própria evolução e desenvolvimento da sociedade, pode-se partir do pressuposto de que sempre a reserva do possível será um limite imanente. Então a pers- 
pectiva deve ser invertida, onde o aplicador do direito, no exercício de ponderação não deve proteger o mínimo essencial, mas conferir o máximo possível por princípio. É também o que me parece afirmar Reis Novais:

o referido condicionamento material dos direitos sociais faz deles - sempre - direitos sob reserva do possivel, pelo que o correspectivo dever jusfundamental que impende sobre o Estado não é, como nos direitos de liberdade, o de garantia da inviolabilidade e possibilidades jurídicas de concretização de um espaço de autodeterminação individual, mas antes o de, tanto quanto possível, promover as condições óptimas de efectivação da prestação estadual em questão e preservar os níveis de realização atingidos ${ }^{42}$.

Ainda que afirme a proteção do mínimo essencial, também Jorge Miranda sustenta que os direitos sociais, sujeitos à reserva do possível, devem ser garantidos numa perspectiva de otimização, nos seguintes termos: em condições econômicas favoráveis deve-se extrair o máximo possível de satisfação das necessidades sociais e realização de todas as prestações; em condições contrárias, as prestações devem ser adequadas a estas, com possível redução; em situações de extrema escassez de recursos ou de exceção constitucional podem ser suspensas; mas mesmo neste último caso deve-se garantir a dignidade da pessoa humana com um conteúdo mínimo de direitos ${ }^{43}$.

\section{CONCLUSÃO}

No propósito de identificar a reserva do possível na interpretação e efetivação dos direitos fundamentais sociais em tempos de crise do Estado Social, apresentada como uma limitação legítima a tais direitos,

\footnotetext{
42 NOVAIS, Jorge Reis. Os princípios constitucionais estruturantes da república portuguesa. Coimbra: Coimbra Editora, 2004, p. 294.

${ }^{43}$ MIRANDA, Jorge. Manual de Direito Constitucional. Tomos II, IV e VI: Coimbra: Coimbra Editora, 2008, p. 443.
} 
relacionamos os limites aos direitos fundamentais à separação de poderes. O que expôs as seguintes questões: a competência do legislador de regular e densificar os direitos constitucionalizados produz um desafio para o judiciário, tanto quando esta regulação implica uma exorbitância deste poder, estabelecendo limites indevidos, como quando não há regulação suficiente e inércia do legislador. De outro lado, a competência discricionária do administrador, tanto quando implica em caracterização de exorbitância de poder, a ser declarada pelo judiciário, como quando o administrador decide nos limites de seu poder, mas em sentido contrário à apreciação ponderada dos princípios e direitos constitucionais. Isto porque a decisão discricionária é política e não deve se condicionar ao julgo complexo dos conflitos de princípios e direitos constitucionais, enquanto que o juiz é vinculado à apreciação ponderada e proporcional diante desses conflitos.

A apreciação vinculada do juiz ocorre porque o juízo político do legislador e a discricionariedade do administrador não podem ser substituídos por igual comportamento judiciário. Ainda que a separação de poderes tenha se flexibilizado num sentido maior de colaboração de poderes, não afetou o seu sentido elementar de distribuição de competências.

O legislador definiu no orçamento e na legislação correspondente aos serviços públicos o rol e a extensão desses, mas haverá uma margem de discricionariedade ao administrador que o juiz não pode interferir. Porém, o administrador está sujeito ao controle de juridicidade dos seus atos, segundo o que foi definido pelo constituinte e aí o controle jurisdicional não afeta a discricionariedade por que aí ela não está.

Por outro lado, a discricionariedade do administrador não significa uma arbitrariedade, deve ocorrer por escolhas dentro de limites razoáveis e proporcionais a garantir minimamente cada direito. Da mesma forma o juízo político do legislador.

A apreciação das doutrinas de solução de conflitos que envolvem normas constitucionais, aplicadas ao problema da reserva do possível, revelou que a ponderação e aplicação do princípio da proporcionalidade, ainda que não resolva a contradição entre a decisão discricionária do administrador e a apreciação ponderada e proporcional do juiz, é a solução mais adequada.

Como dito anteriormente, o juiz não dispõe apenas do argumento irrefutável da limitação de recursos, vincula-se também à prevalência e normatividade dos direitos. Como se trata de uma decisão vinculada, 
porém com duas variáveis, a determinação, caso a caso, do direito devido é um juízo aberto e de difícil controle, e que permite imiscuir com a valoração subjetiva e pessoal do próprio juiz.

A solução que apresentamos, como garantia de vinculatividade do juiz, é a perspectiva de otimização dos direitos sociais diante do quadro de limitação pela reserva do possível. Diante da fragilidade na determinação de um mínimo essencial, o juiz está vinculado à opção possível que proporcione o nível maior de efetividade dos direitos sociais.

\section{REFERÊNCIAS BIBLIOGRÁFICAS}

ALEXY, Robert. Teoria dos direitos fundamentais. São Paulo: Malheiros, 2008.

ANDRADE, José Carlos Vieira de. Os direitos fundamentais na Constituição portuguesa de 1976. Coimbra: Livraria Almedina, 1983.

BARROSO, Luís Roberto. Temas de Direito Constitucional. Vol. I. Rio de Janeiro/São Paulo: Renovar, 2001.

BOLZAN DE MORAIS, José Luis. O Estado e seus limites, reflexões iniciais sobre a profanação do Estado Social e a dessacralização da modernidade. IN: OLIVEIRA NETO, Francisco José Rodrigues e outros (org.) Constituição e Estado Social: os obstáculos à concretização da Constituição. Coimbra: Coimbra Editora, 2008. BONAVIDES, Paulo. Curso de Direito Constitucional. São Paulo: Malheiros, 2007.

CANOTILHO, José Joaquim Gomes. Metodologia 'fuzzy' e 'camaleões normativos' na problemática atual dos direitos econômicos, sociais e culturais. In: Canotilho, J.J. Gomes (coord.). Estudos sobre direitos fundamentais. Coimbra: Editora Coimbra, 2004. . Direito Constitucional. Coimbra: Almedina, 1992.

CANOTILHO, J.J. Gomes e STRECK, Lênio. Entre discursos e culturas jurídicas. Coimbra: Coimbra Editora, 2006.

DWORKIN, Ronald. Levando os direitos a sério. São Paulo: Martins Fontes, 2002.

FARIA, José Eduardo ET. AL. Direito e Globalização Econômica. Implicações e perspectivas. São Paulo: Malheiros, 2010. 
GARCIA, Emerson. Conflito entre normas constitucionais: esboço para uma teoria geral. Rio de Janeiro: Lumen Juris. 2008.

ESTORNINHO, Maria João. A fuga para o direito privado. Coimbra: Almedina, 1996.

MELLO, Celso Antônio Bandeira de. Curso de direito administrativo. São Paulo: Malheiros, 2003.

MIRANDA, Jorge. Manual de Direito Constitucional. Tomos II, IV e VI: Coimbra: Coimbra Editora, 2008.

NOVAIS, Jorge Reis. As restrições aos direitos fundamentais não expressamente autorizadas pela Constituição (tese de doutoramento). Lisboa: Faculdade de Direito de Lisboa, 2002.

- Os princípios constitucionais estruturantes da república portuguesa. Coimbra: Coimbra Editora, 2004.

OLIVEIRA NETO, Francisco José Rodrigues e outros (org.) Constituição e Estado Social: os obstáculos à concretização da Constituição. Coimbra: Coimbra Ed. 2008.

PIOVESAN, Flávia. Direitos Humanos e o Direito Constitucional Internacional. São Paulo: Saraiva, 2007.

ROSANVALLON, Pierre. A crise do Estado-providência. Brasília: Ed. Da UNB; Goiânia: Ed. Da UFG, 1997.

SARLET, Ingo Wolfgang e TIMM, Luciano Benetti. (org.) Direitos fundamentais - orçamento e reserva do possível. Porto Alegre: Livraria do Advogado, 2008.

STREK, Lênio Luiz. Constituição e hermenêutica em países periféricos. IN OLIVEIRA NETO, Francisco José Rodrigues e outros (org.) Constituição e Estado Social: os obstáculos à concretização da Constituição. Coimbra: Coimbra Editora, 2008.

SOARES, Guilherme. Restrições aos direitos fundamentais: a ponderação é indispensável? In: MIRANDA, Jorge (coord.). Estudos em homenagem ao Professor Doutor Joaquim Moreira da Silva Cunha. Lisboa: FDUL, 2005. 